\title{
Retropharyngeal abscess with secondary osteomyelitis and epidural abscess: proposed pathophysiological mechanism of an underrecognized complication of unstable craniocervical injuries: case report
}

\author{
Carlos R. Goulart, MD, ${ }^{1}$ Tobias A. Mattei, MD, ${ }^{2}$ Mariano E. Fiore, MD, ${ }^{1}$ William J. Thoman, MD, ${ }^{1}$ and \\ Ehud Mendel, MD'
}

1Department of Neurological Surgery, The Ohio State University Wexner Medical Center and The James Cancer Hospital, Columbus, Ohio; and 'Department of Neurosurgery, InvisionHealth Brain \& Spine Center, Buffalo, New York

\begin{abstract}
Because of the proximity of the oropharynx (a naturally contaminated region) to the spinal structures of the craniocervical junction, it is possible that small mucosal lacerations in the oropharynx caused by unstable traumatic craniocervical injuries may become contaminated and lead to secondary infection and osteomyelitis. In this report, the authors describe the case of a previously healthy and immunocompetent patient who developed a large retropharyngeal abscess with spinal osteomyelitis after a high-energy craniocervical injury. This unusual report of osteomyelitis with a delayed presentation after a high-energy traumatic injury of the craniocervical junction highlights the possibility of direct injury to a specific area in the oropharyngeal mucosa adjacent to the osteoligamentous structures of the craniocervical junction, an overall underrecognized complication of unstable craniocervical injuries.
\end{abstract}

http://thejns.org/doi/abs/10.3171/2015.4.SPINE14952

KEY WORDS traumatic craniocervical injuries; retropharyngeal abscess; traumatic spinal injuries; osteomyelitis; whiplash; epidural abscess; trauma; infection

I NFECTIONS of the vertebral column can result in vertebral osteomyelitis with or without epidural abscess. ${ }^{15}$ Vertebral osteomyelitis is a relatively rare condition and comprises $2 \%-7 \%$ of all hematogenous bone infections, but their incidence appears to be increasing in recent years compared with the first half of the 20th century. ${ }^{5}$ Only $6.5 \%$ of these infections are located in the cervical region, the least commonly affected area of the spine..$^{36,38}$ Spinal epidural abscess is also a rare diagnosis with an incidence of approximately 0.2-2 cases per 10,000 admis-

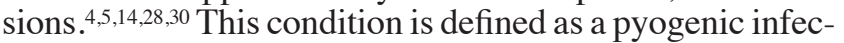
tion between the vertebral body and dura mater covering the spinal cord. 8,30,40 The epidural space can be seeded with infection by a variety of mechanisms, including hematogenous spread $(50 \%)$, direct extension from adjacent infection $(33 \%)$, inoculation from spinal procedures $(15 \%)$, and other mechanisms., 52,39 Although Staphylococcus aureus causes approximately two-thirds of spinal abscesses, other infecting pathogens, including gram-positive and -nega- tive bacteria and anaerobic bacteria, are possible causative agents. . $^{20,21,30,34}$

The rate of misdiagnosis at presentation for vertebral osteomyelitis and epidural abscess is still high (50\%). ${ }^{6,29,46}$ The wide variation in clinical presentations makes it difficult to conduct any large-scale observational studies. Furthermore, such a study would raise ethical concerns, and, consequently, the decision making and management have been largely dependent on empirical experience, animal studies, and literature case reports.

Because of the high risk for tragic consequences in these conditions, surgeons and clinicians must be aware of the less frequent causes of these infections, such as direct contamination after surgery (including discectomy), penetrating trauma, closed trauma, or contiguous extension of an infection located in the prevertebral spaces. ${ }^{17,27,45}$ One of these spaces, the retropharyngeal space (RPS), may be secondarily contaminated and may lead to the formation of an abscess and osteomyelitis. ${ }^{26}$

ABBREVIATIONS ALL = anterior longitudinal ligament; MSSA = methicillin-sensitive Staphylococcus aureus; OSU = The Ohio State University; RPS = retropharyngeal space; SEA = spinal epidural abscess; TLIF = transforaminal lumbar interbody fusion.

SUBMITTED October 28, 2014. ACCEPTED April 10, 2015.

INCLUDE WHEN CITING Published online September 25, 2015; DOI: 10.3171/2015.4.SPINE14952. 
We propose in this paper that, because of the proximity of the oropharynx mucosa, a naturally contaminated region, and the osteoligamentous structures of the craniocervical junction, especially in the area adjacent to the anterior arch of C-1, a secondary infection leading to retropharyngeal abscess formation and resultant contiguous osteomyelitis with epidural abscess formation might be caused by the introduction of microorganisms into the RPS due to minor mucosal lacerations. As an illustration, we report the case of a previously healthy and immunocompetent patient who developed a large retropharyngeal abscess with spinal osteomyelitis and epidural abscess after a high-energy cervical trauma with a subsequent unrecognized unstable craniocervical injury. To our knowledge, this is the first report that specifically highlights this proposed pathophysiological mechanism.

\section{Case Report}

This 50-year-old man with no significant prior medical history was involved in a motor vehicle accident in which he struck a deer at approximately 30 miles per hour. He did not seek medical attention at the time of the accident since he had only mild neck pain. After 5 days his neck pain worsened and he underwent a session of chiropractic manipulations.

The following day the patient developed fevers as high as $102.8^{\circ} \mathrm{F}\left(39.3^{\circ} \mathrm{C}\right)$ and went to an urgent care facility. Because of associated nasal congestion at the time, he was prescribed Bactrim for a supposed sinus infection. His clinical picture worsened with fever, chills, drenching sweats, worsening neck pain, neck weakness, and a subjective truncal weakness.

Around 40 days after the accident and with the progression of his symptoms, the patient went back to the urgent care facility and was advised to go to the emergency department, but he decided not to follow the recommendation. Shortly after, while at home, he developed a sudden onset of weakness in all 4 extremities and was brought by ambulance to an outside hospital for evaluation.

Workup revealed a C-2 fracture with spinal cord compression and findings suggestive of osteomyelitis with epidural abscess (Fig. 1). CT angiography demonstrated vertebral artery compression and occlusion on the right side by the fractured segment level (C2-3). Blood cultures grew methicillin-sensitive $S$. aureus (MSSA), and the patient was started on a regimen of cefazolin. Additionally, at this same hospital, the patient underwent surgery for posterior decompression and cervical stabilization performed with the placement of 2 short screws, a transforaminal lumbar interbody fusion (TLIF) cage between the spinous processes, and wiring that led to coronal deformity (Fig. 2A-D).

On postoperative Day 9, while still in the hospital, the patient's neck slouched forward while he was seated and he developed sudden-onset shortness of breath and quadriplegia. The patient passed out, and when he was laid down he was able to regain consciousness and breathe.

The patient was then transferred to our emergency department with Grade 0/5 strength in all extremities, with the exception of minimal strength in the left leg. A new imaging examination with cervical MRI demonstrated
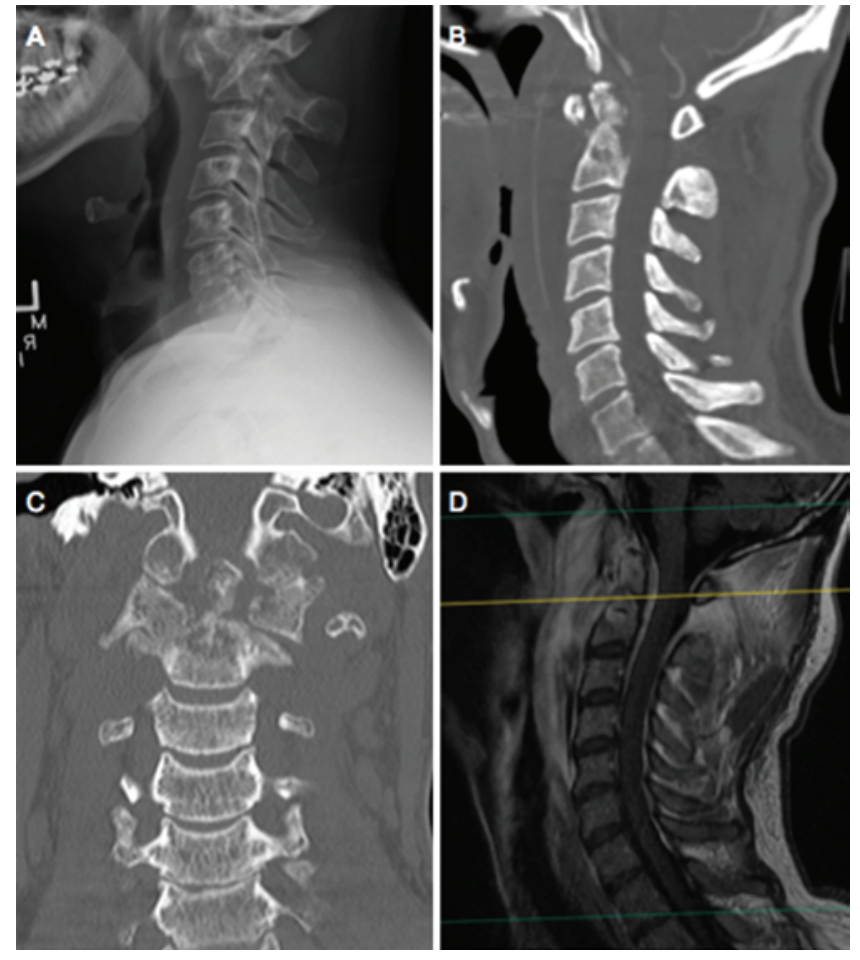

FIG. 1. Imaging evaluation at the outside hospital before the index procedure around 40 days after the accident. A: Lateral radiograph demonstrating the C-2 fracture. B and C: Sagittal and coronal CT scans demonstrating the C-2 fracture with a pattern of bony destruction suggestive of osteomyelitis. D: Sagittal T1-weighted MR image showing the retropharyngeal abscess and osteomyelitis with contrast enhancement of the bony structures and a contrast-enhancing phlegmon in the anterior portion of the epidural space. Figure is available in color online only.

worsening of the epidural abscess extending from the clivus to $\mathrm{C} 3-4$ levels and diffuse cord edema from the craniocervical junction to $\mathrm{C}-6$ along with $\mathrm{C} 1-2$ subluxation with a left lateral mass displacement of $9 \mathrm{~mm}$. Severe bone irregularity was noted, suggesting severe osteomyelitis in the occipital condyles and C1-2 vertebrae. There was also enhancement extending into the paraspinal soft tissues consistent with abscess with a ring-enhancing collection from the occipital region to the C-6 level. The patient was then admitted to the neurosurgery department for further workup.

During the hospitalization, the patient developed several complications related to dysautonomia, including hypoxia, acute respiratory insufficiency, and a postoperative deep vein thrombosis in the right upper extremity. For the MSSA bacteremia and spine osteomyelitis, the antibiotic regimen was changed to intravenous Unasyn and intravenous vancomycin for a total period of 6 weeks. According to infectious disease recommendations, the patient should be initially treated with 7 days of intravenous antibiotic therapy before being submitted to surgical reintervention to reduce the risks of infection during insertion of the new hardware. On the 5th day after admission, the patient was placed in cervical traction with the weight increased in a slow fashion (increase of 5 lbs every 12 hours with sequential radiographs) to obtain reduction of the deformity (Fig. 3). 

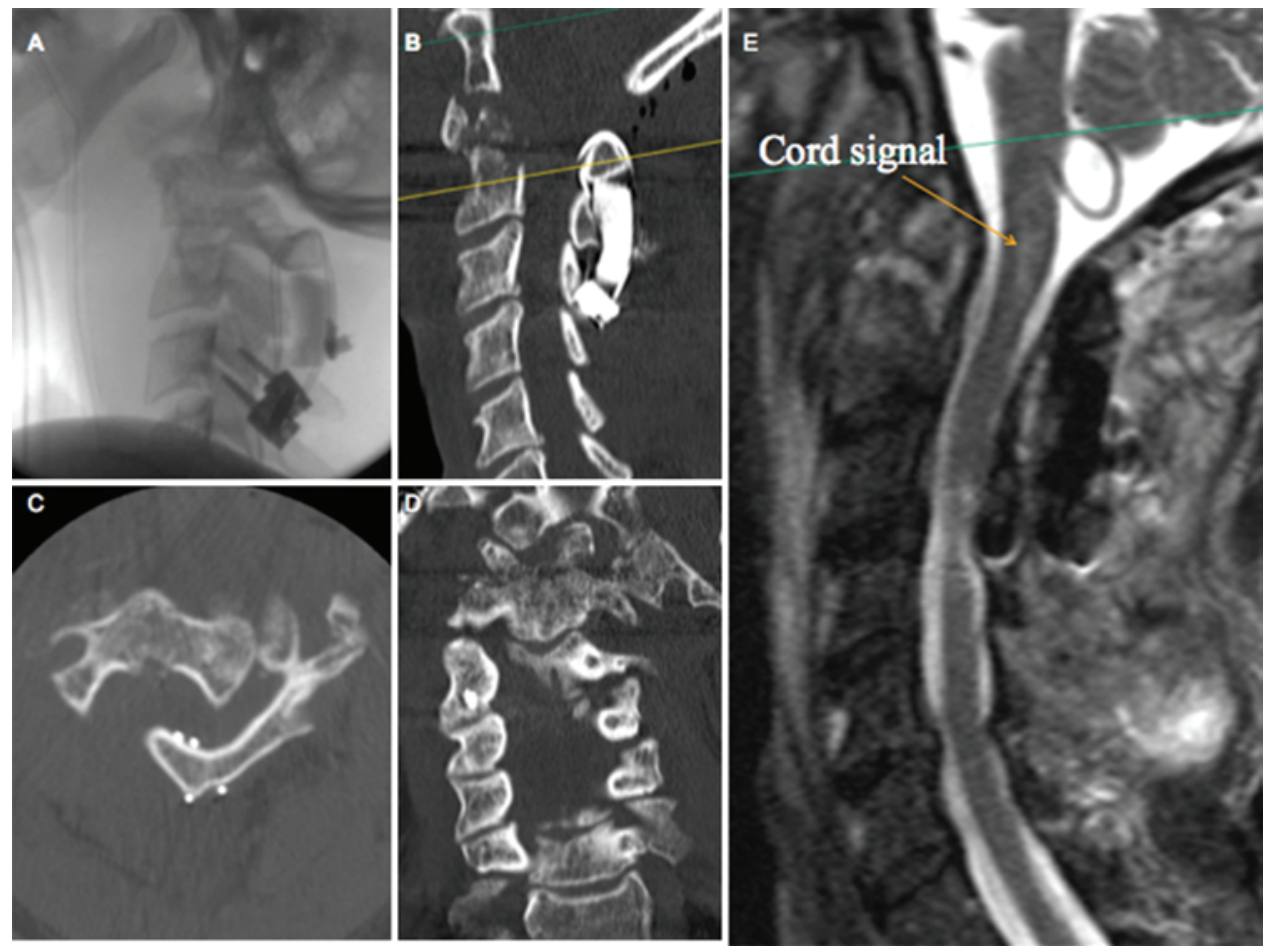

FIG. 2. A: Postoperative lateral radiograph showing the construct implanted at the outside hospital with the placement of 2 short screws at C-3, a TLIF cage between the spinous processes of C-2 and C-3, and wiring, which seems to have led to significant coronal instability. B-D: Sagittal (B), axial (C), and coronal (D) CT scans obtained during the postoperative period of the first surgery at the outside hospital, demonstrating the coronal instability subsequent to the surgery. E: Sagittal T2-weighted MR image highlighting the spinal cord signal at the craniocervical junction. Figure is available in color online only.

After obtaining significant reduction of the deformity, the patient underwent surgical intervention 9 days after admission. The old construct was removed, and an occiput to C-4 arthrodesis with fusion was performed with open reduction and correction of the deformity between the occiput and C-2 (Fig. 4). An intraoperative CT angiogram utilizing the $\mathrm{O}$-Arm was performed to ensure that the remaining vertebral artery was patent.

Postoperative radiographs and CT scans demonstrated optimal reduction of both the sagittal and coronal imbalance (Fig. 5). Following surgery, the patient was kept in an external halo orthosis for 8 weeks after discharge. The halo was removed after the findings of upright radiographs with and without the halo were similar and a CT scan demonstrated fusion in progress. At the last follow-up 5 months after surgery, the patient had regained full strength in all his extremities (Fig. 6A-C). The most recent MRI study demonstrated reduction in the size of the abnormal T2 signal in the spinal cord (Fig. 6D).

\section{Discussion}

The understanding of the anatomy of the RPS and its relationship with the osteoligamentous structures in the cervical area is essential to understand our proposed pathophysiological mechanism.

The RPS is bordered anteriorly by buccopharyngeal fascia and posteriorly by prevertebral fascia. The RPS can be divided into an anterior and a posterior compartment by the thin alar fascia that comes from the deep cervical fascia. The anterior compartment extends from the skull base to the T- 4 vertebral body. The posterior compartment extends inferiorly to the level of the diaphragm. Head and neck infections might spread to the posterior mediastinum through the RPS. The RPS can be further divided relative to the hyoid bone, with the suprahyoid space containing retropharyngeal lymph nodes and fat, while the infrahyoid area contains only fat. ${ }^{48}$

The RPS has a very close relationship with the craniocervical junction, a complex articulation between the cranium and upper cervical spine (C1-2) with several bony and ligamentous structures, including the transverse atlantal ligament, paired alar ligaments, and the apical ligament of the dens. Lesions at this articulation can lead to hematoma formation into the RPS. The main anatomical structures that could be sources of hematoma when injured are the longus capitis and longus colli muscles, the anterior longitudinal ligament, and the vertebral artery branches.

In particular, the anterior arch of C-1 is easily accessible through the retropharyngeal mucosa, as can be seen in our cadaveric endoscopic endonasal dissection (Fig. 7). We performed this dissection on a de-identified cadaveric specimen at the Anatomy Laboratory Toward Visuospatial Surgical Innovations in Otolaryngology and Neurosurgery at the Wexner Medical Center at The Ohio State University (OSU), which is certified by regulatory agencies in dealing with the use of human tissues and cadaveric studies. Our dissection highlights the very close relationship with the oropharynx mucosa, an area inhabited not only by normal flora but also potentially by virulent 

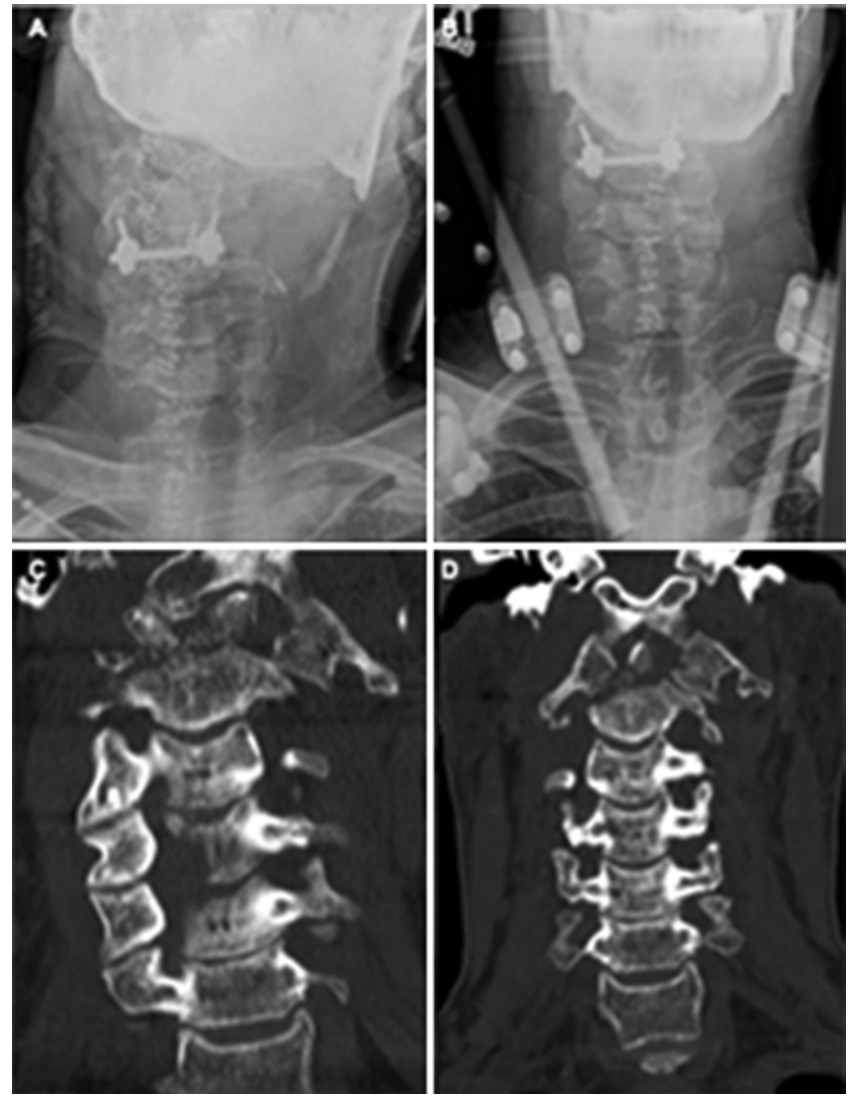

FIG. 3. A and C: Posteroanterior radiograph and coronal CT scan obtained at admission to OSU before the patient was placed in an external halo orthosis. B and D: Posteroanterior radiograph and coronal CT scan obtained after external halo orthosis placement. On the 5th day after admission, the patient was placed in cervical traction with increased weights added in a slow fashion (increase of $5 \mathrm{lbs}$ every 12 hours with sequential radiographs) to obtain reduction of the deformity. After surgery at our institution, the patient remained in the brace for 8 weeks.

bacteria. Thus, minor mucosal lacerations might provide a possible path for bacterial invasion and subsequent abscess development in the RPS given a setting of a highenergy craniocervical injury, as demonstrated in our dynamic illustration (Fig. 8). 3,48

In patients with degenerative changes in the spine, the risk of a mucosal tear might be even greater. Robinson et al. described a case of perforation of the posterior pharyngeal wall with abscess formation by an anterior marginal osteophyte at the time of hyperextension injury of the cervical spine. The abscess communicated with the epidural space via the disrupted intervertebral disc, leading to the delayed onset of upper airway obstruction and tetraparesis. $^{35}$

Another interesting case reported by Wadie et al. describes a patient with a sewing pin impaction in the laryngeal introitus, with late development of cervical spondylodiscitis after an uneventful removal of the foreign body. The authors concluded that the patient had a microperforation of the posterior pharyngeal wall that was not visible during the endoscopy procedure performed at his initial evaluation. ${ }^{50}$ This conclusion supports that even minor trauma to the posterior oropharyngeal wall might

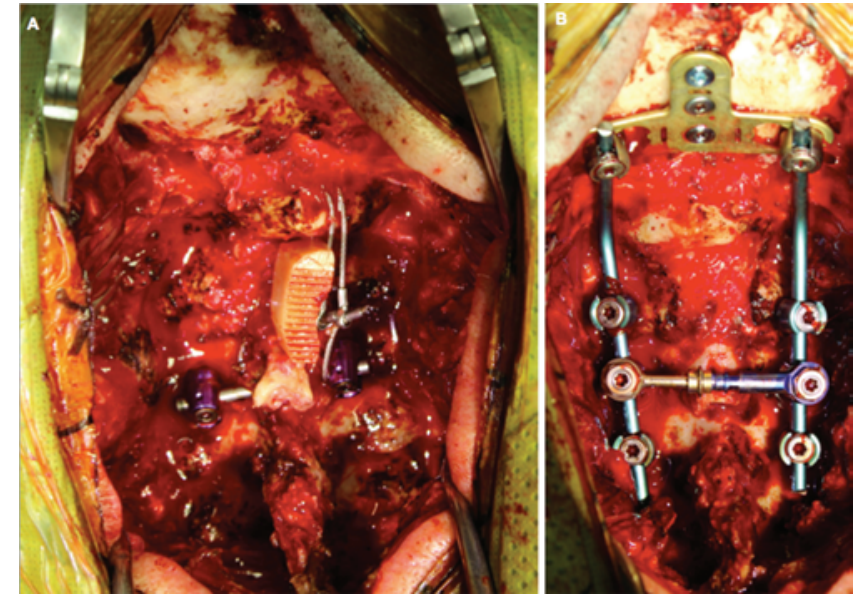

FIG. 4. A: Intraoperative image obtained during exposure of the previous construct placed at an outside hospital, demonstrating the laminectomy and the TLIF cage placed between the spinous processes as well as the wiring. B: Intraoperative image obtained after the previous construct was removed and the craniocervical fixation was performed at our institution to properly address the instability.

be a source of infection to the retropharyngeal space and, consequently, the spine.

Additionally, cases in the literature confirm that the forces acting in a whiplash injury could be strong enough to cause esophageal perforation. ${ }^{49}$ In 1960, Morrison described a patient in whom hyperextension of the cervical spine had ruptured the esophagus; the patient died of me-


FIG. 5. Postoperative lateral (A) and posteroanterior (B) radiographs and sagittal (C) and coronal (D) CT scans (C and D) demonstrating optimal reduction of both the sagittal and coronal imbalance. 


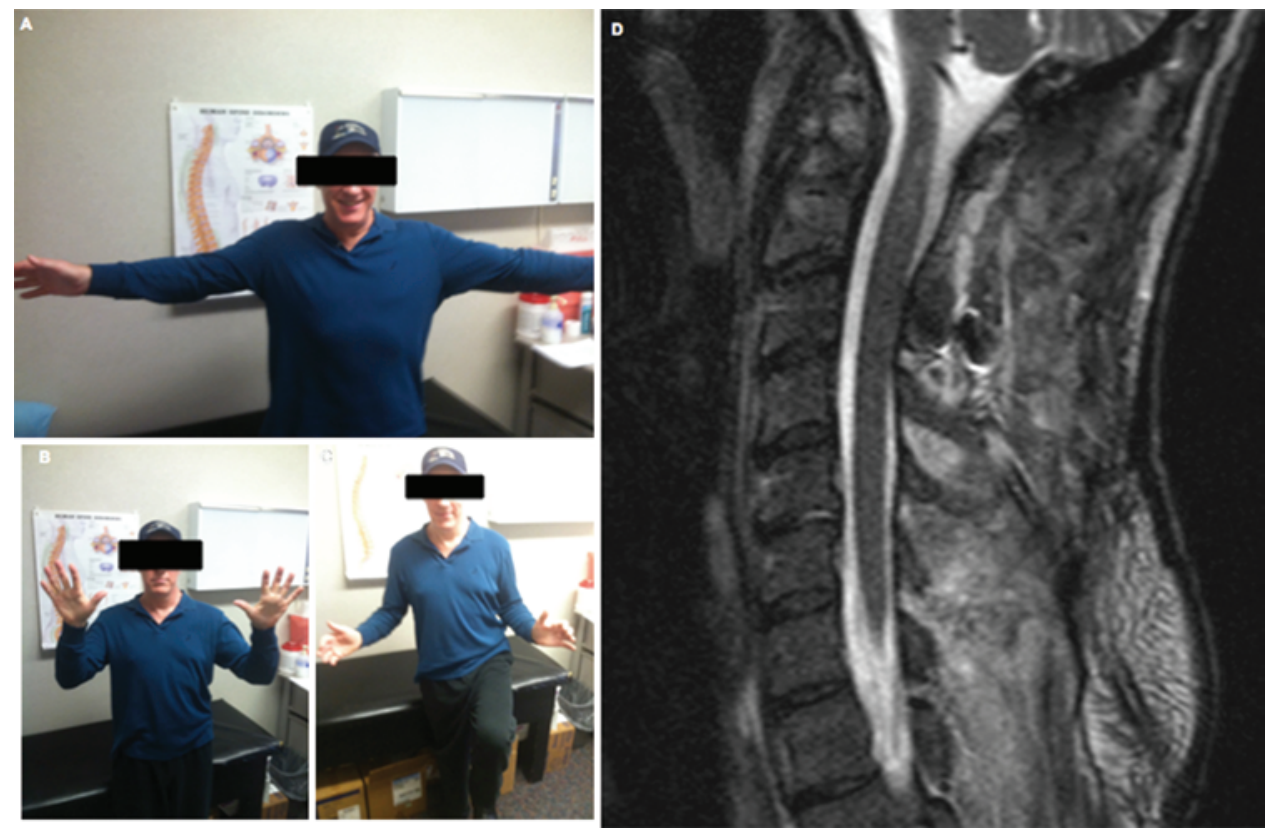

FIG. 6. A-C: In the last follow-up 5 months after surgery, the patient had regained full strength in all his extremities. D: The most recent sagittal MR image demonstrated reduction in the size of the abnormal T2 signal in the spinal cord. Figure is available in color online only.

diastinitis and bronchopneumonia 2 weeks after injury. ${ }^{25}$ In 1976, Splener and Benfield reported on a patient with esophageal trauma in whom the delayed diagnosis and treatment contributed to the development of an abscess that require surgical drainage. ${ }^{43,49}$ In this context, it is also feasible that a microrupture to the fragile retropharyngeal mucosa specifically located in the area adjacent to the anterior arch of C-1 could occur after whiplash injuries.

Moreover, esophageal perforation after radiation and chemotherapy is described as a possible cause of spinal abscess, and one of the proposed mechanisms is via a direct extension through a fistula formed between the pharynx and the prevertebral fascia due to radiation necrosis with posterior extension to the spine, potentially causing osteomyelitis and abscess formation..$^{13}$ Even small traumatic lesions such as the one caused by a fish bone are described as possible sources of infection to adjacent areas. ${ }^{17}$

Retropharyngeal hematoma, which is a known possible complication of trauma described in the literature, is usually treated conservatively with observation. It is possible

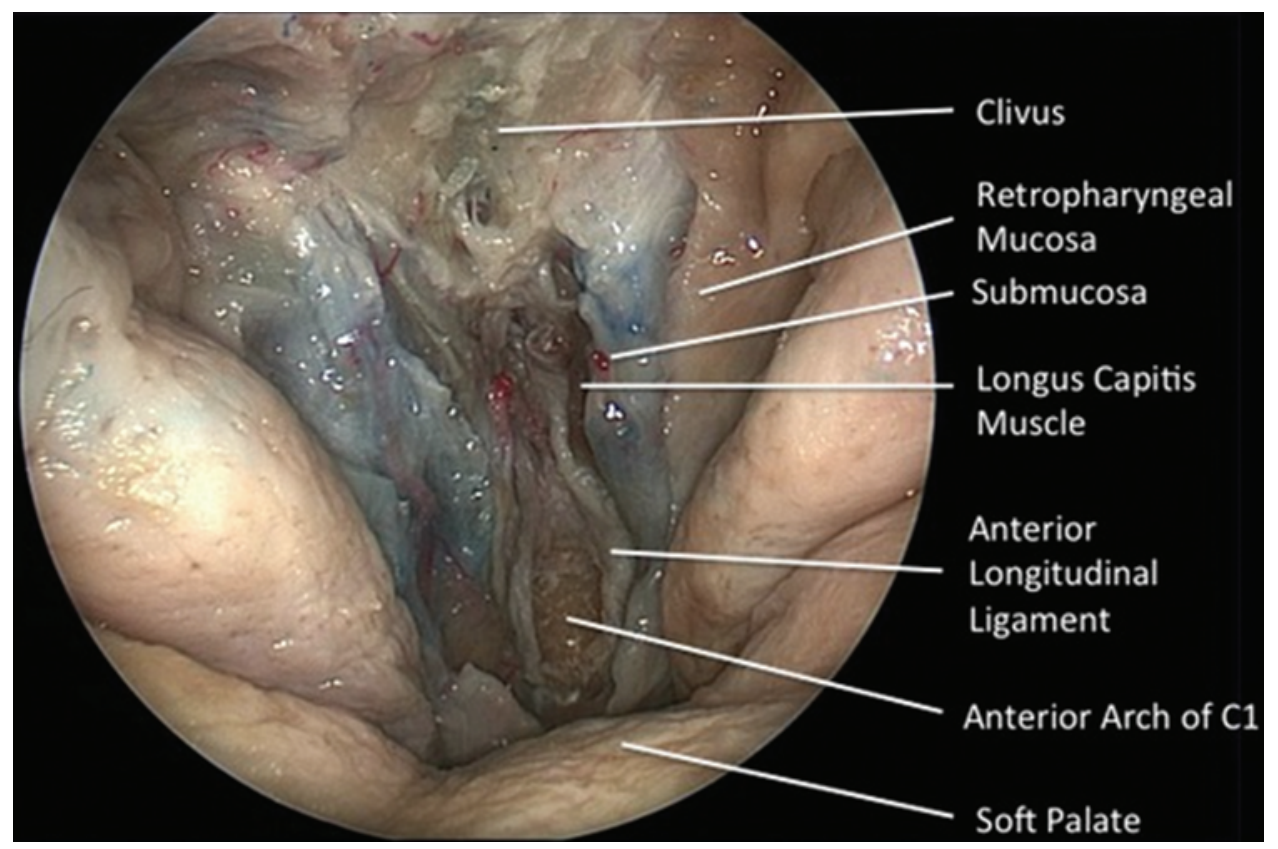

FIG. 7. Endoscopic endonasal dissection demonstrating the close relationship between the retropharyngeal mucosa, a naturally contaminated region, and the anterior arch of C-1. 


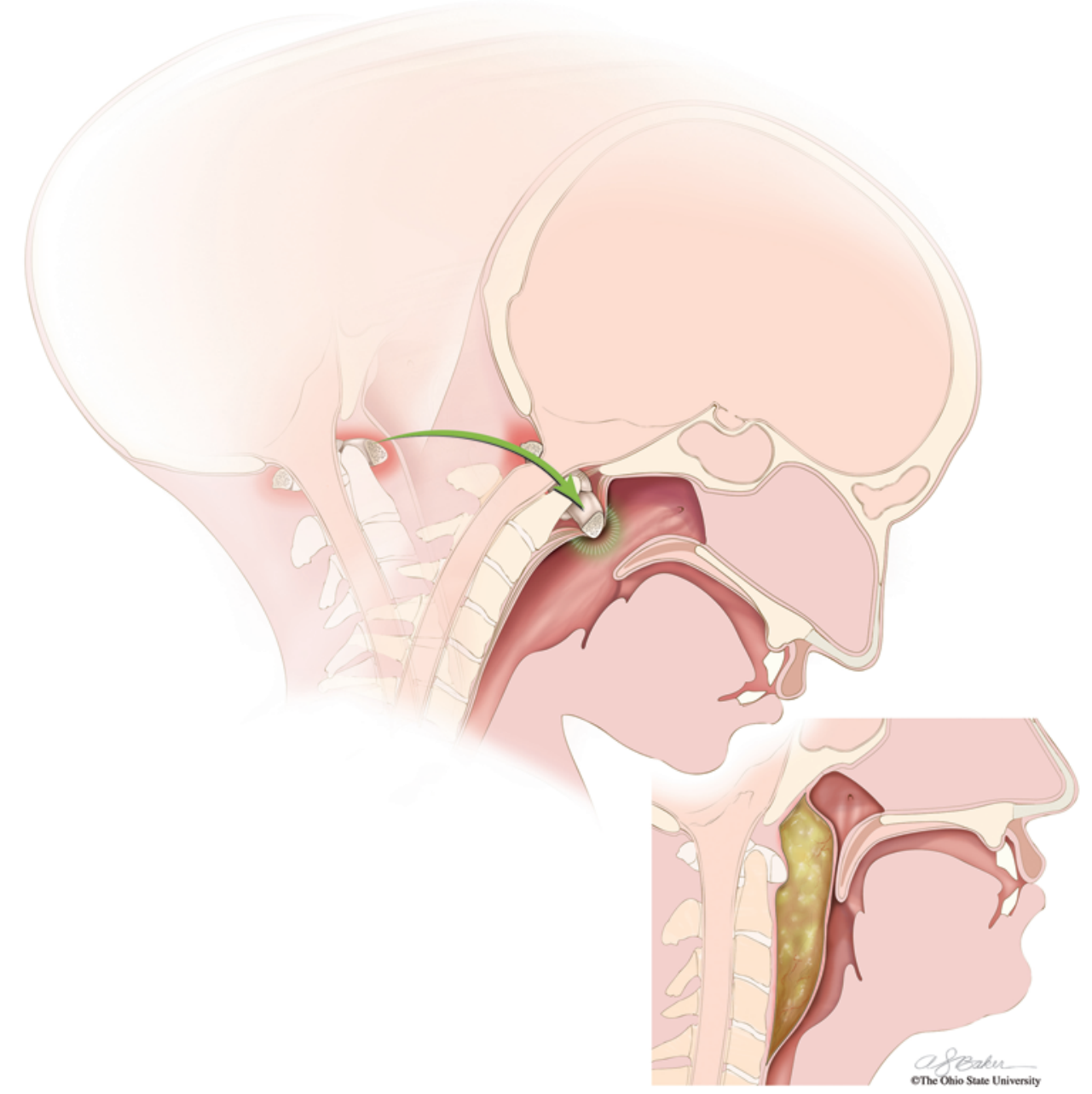

FIG. 8. Illustration demonstrating the dynamic relationship between the anterior arch of C-1 and the thin retropharyngeal mucosa in the setting of a high-energy cervical injury, causing a microlaceration in this portion of the mucosa with consequent invasion of microorganisms into the retropharyngeal space, potentially leading to an infection. Copyright The Ohio State University Health Sciences Library Medical Visuals. Published with permission.

that if there is a microlesion to the oropharyngeal wall with bacteria inoculation, the hematoma might function as a medium of culture for the bacteria to grow and lead to an abscess with posterior involvement of the cervical spine and epidural space. ${ }^{23,27}$

In regard to retropharyngeal abscesses, the most common cause is bacterial infection that originates from the nasopharynx, middle ear, sinuses, or tonsils. Because the RPS lymph nodes degenerate during adolescence, there is a decreased incidence of spontaneous retropharyngeal abscess in adults. ${ }^{2}$ Nonetheless, if left untreated, these abscesses can lead to additional complications, such as thrombosis, airway obstruction, pericarditis, and rarely vertebral osteomyelitis. When vertebral osteomyelitis occurs, serious consequences such as vertebral bone destruction and epidural abscess may ensue.

To date, we could find no description in the literature about oral mucosal perforation in the thinner portion of this structure located in the area adjacent to the anterior arch of C-1 as a cause of retropharyngeal abscess and subsequent osteomyelitis. In addition, whereas patients who develop retropharyngeal abscess usually have some degree of immunodeficiency, our patient was young and immunocompetent. ${ }^{13,46}$

\section{Infection Progression and Craniocervical Instability}

There are strong clinical and biomechanical studies supporting that soft-tissue injuries of the cervical spine can lead to instability, which could have been the cause of our patient's unstable craniocervical injury that was previously not recognized. Subacute instability of the cervical spine has been reported in patients presenting with neck pain and normal findings on radiographs who subsequently developed clinical instability, most likely due to ligamentous injury. ${ }^{12}$ In vitro investigations have demonstrated that transection or injury to the anterior longitudinal ligament (ALL) and anterior annulus resulted in increased flexibility under extension loading, implying that injury to these components could lead to instability ${ }^{16,33,47}$ Ivancic et al. found that the ruptured ligaments were associated with significantly greater dynamic intervertebral extension, peak ligament strain, and joint laxity compared with the uninjured ligaments. ${ }^{16}$

We also agree that these lacerations in the ALL could 
serve as the path through which the infection could progress to osteomyelitis and epidural abscess. Harris and Yeakley reviewed the MR images obtained in 8 adults with acute hyperextension-dislocation of the cervical spine. The images were obtained to evaluate damage to the spinal cord. All 8 patients had disruption of the ALL and of the annulus of the intervertebral disc. ${ }^{11}$ Similar injuries have also been discovered at surgery and autopsy.,19 Whiplash simulations using cadavers and monkeys have also produced ALL tears and anterior disc detachments. ${ }^{16,41,54}$ Along these lines, a meta-analysis by Reihsaus et al. verified that closed trauma might play a role in spinal epidural abscess since about $10 \%$ of patients with spinal epidural abscess of unknown origin had a history of extraspinal or spinal trauma. ${ }^{30}$

Moreover, destruction of bone caused by the osteomyelitis itself contributes to the craniocervical instability. The vascular spread of bacteria and microthrombosis due to pus creates an increased intraosseous pressure that impairs the blood flow to the vertebrae and intervertebral discs. ${ }^{22,51,52}$ This may lead to ischemic necrosis and destruction of the vertebrae and intervertebral discs with consequent spinal deformity. Another proposed mechanism for bone destruction is through the production of destructive enzymes by bacterial agents such as $S$. aureus. The most important of these proteolytic enzymes is hyaluronidase, which is used by the bacteria as an invasive mechanism into the connective tissue. It causes destruction of structures such as the annulus fibrosus, leading to biomechanical instability and deformity. ${ }^{18,44}$ In a cohort published by Srinivasan et al., the overall risk of developing a deformity with osteomyelitis was 44\% (21/48). Of these 21 deformities, 14 involved kyphosis only, 5 involved subluxation only, and 2 involved both kyphosis and subluxation. ${ }^{44}$

Infectious lesions within the RPS and extending to the spine are difficult to diagnose clinically; the first symptoms to appear are unspecific, and a high level of suspicion is necessary to make the diagnosis. For instance, our patient presented initially with vague symptoms that progressed to weakness, falls, 30-lb weight loss, spasms, headaches, finger numbness, fevers, and chills. As in our case, patients present with more specific symptoms only at a later stage when the degree of spread is advanced, and neurological deficits and the destruction of the vertebral bodies due to osteomyelitis could be already permanent.

Despite spinal epidural abscess (SEA) being a rare condition, delay in diagnosis may lead to permanent neurological deficit, sepsis, and even death. The mortality of SEA has been reported to be as high as $16 \% .^{10,34,37} \mathrm{~A}$ study by Tang et al. in 2002 revealed that the initial accurate diagnosis rate was as low as $26 \% .^{46}$ Unfortunately, as many patients are initially misdiagnosed, they will have a poor prognosis; therefore, these patients should be assessed in detail.

According to the available literature, the main symptom of the SEA is pain, followed by common signs of infection, such as fever and malaise. The classic diagnosis of SEAs with mechanical pain, tenderness, fever, and neurological abnormalities is likely only enough to capture a maximum of $10 \%$ of patients. According to a study by Davis et al. the typical clinical presentation of retropharyngeal abscess is acute to subacute onset of neck pain, with or without associated dysphagia and odynophagia, which might lead to weight loss-as in our case-and low-grade fever. ${ }^{6}$ Less frequently, patients might present with clearer symptoms, such as airway distress, high-grade fever $\left(>101^{\circ} \mathrm{F}\right)$, drooling, trismus, limited neck motion, head tilt or torticollis, and noisy breathing. ${ }^{31}$

In this unclear clinical setting the key diagnostic tools are the imaging findings. Plain radiographs are more likely to show normal findings in the acute phase, although soft-tissue changes may be present. Bony changes on plain radiographs are usually present in chronic infections. CT is also helpful in evaluating the amount of bone involvement. Nonetheless, contrast-enhanced MRI is the modality of choice for identifying the spinal infection, because of its excellent visualization of the abscess itself, and the infection foci in the vertebrae, disc space, or paraspinal region. . $^{422,38}$

In our case the patient had not only an unstable craniocervical injury but also the presence of a purulent bacterial empyema or phlegmon in the epidural space overlying the spinal cord. Therefore, this case was considered a surgical emergency with the intent to decrease the likelihood of neurological deficits caused by infection progression. Studies in the literature decades ago demonstrated in rabbits that diffuse thrombosis of the underlying vasculature is the probable cause of neurological decline in this condition. 8,9

Although surgical treatment of neurologically intact patients with vertebral osteomyelitis alone or minimal epidural abscess is quite controversial, vertebral osteomyelitis and epidural abscess associated with neurological deficits are considered surgical emergencies. ${ }^{1,6,24,42,53}$ Since local inflammation leading to thrombophlebitis or venous congestion is thought to be a possible mechanism of neurological injury, surgical debridement is useful to remove the inciting organisms and factors to reduce the risk of vascular-related neurological complications. ${ }^{8}$

Aggressive treatment of the prevertebral abscess is the key to decrease mortality; the most recommended management would be surgical drainage, followed by systemic antibiotics. The patient's neurological status just after surgery is the main prognosis tool..$^{39}$ About $5 \%$ of the patients with spinal epidural abscess die, usually of progressive sepsis, consequent meningitis, and complications due to underlying diseases. ${ }^{5}$ In our case, the patient experienced a severe neurological deficit while he was in the hospital, which allowed prompt management and recovery of his neurological function despite the complications encountered..$^{10}$

\section{Conclusions}

Retropharyngeal abscess leading to spinal osteomyelitis is usually a very challenging clinical situation, especially in the setting of craniocervical instability and secondary deformity. By presenting an illustrative surgical case, this article highlights the relationship between a routine anatomical finding (the short distance between the oropharyngeal mucosa and the anterior arch of C-1) and the possibility of osteomyelitis occurring after high-en- 
ergy craniocervical trauma. The pathophysiology of such injury would involve direct disruption of the oropharyngeal mucosa by the unstable osseous structures, leading either to a direct communication with the oropharyngeal space or to the formation of a retropharyngeal hematoma that may become infected. Ultimately, early diagnosis and treatment of vertebral osteomyelitis is highly dependent on physicians' awareness of such potential complications of craniocervical junction trauma, which, in our opinion, has been highly underrecognized in the spinal literature. Finally, this article emphasizes the necessity of further combined histological/biomechanical studies to evaluate the effects of progressive levels of craniocervical instability upon the integrity of the oropharyngeal mucosa.

\section{References}

1. Akalan N, Ozgen T: Infection as a cause of spinal cord compression: a review of 36 spinal epidural abscess cases. Acta Neurochir (Wien) 142:17-23, 2000

2. Boyd R, Massey R, Duane L, Yates DW: Whiplash associated disorder in children attending the emergency department. Emerg Med J 19:311-313, 2002

3. Crockard HA: Transoral surgery: some lessons learned. Br J Neurosurg 9:283-293, 1995

4. Curry WT Jr, Hoh BL, Amin-Hanjani S, Eskandar EN: Spinal epidural abscess: clinical presentation, management, and outcome. Surg Neurol 63:364-371, 2005

5. Darouiche RO: Spinal epidural abscess. N Engl J Med 355:2012-2020, 2006

6. Davis DP, Wold RM, Patel RJ, Tran AJ, Tokhi RN, Chan TC, et al: The clinical presentation and impact of diagnostic delays on emergency department patients with spinal epidural abscess. J Emerg Med 26:285-291, 2004

7. Davis SJ, Teresi LM, Bradley WG Jr, Ziemba MA, Bloze AE: Cervical spine hyperextension injuries: MR findings. Radiology 180:245-251, 1991

8. Feldenzer JA, McKeever PE, Schaberg DR, Campbell JA, Hoff JT: Experimental spinal epidural abscess: a pathophysiological model in the rabbit. Neurosurgery 20:859-867, 1987

9. Feldenzer JA, McKeever PE, Schaberg DR, Campbell JA, Hoff JT: The pathogenesis of spinal epidural abscess: microangiographic studies in an experimental model. J Neurosurg 69:110-114, 1988

10. Ghobrial GM, Beygi S, Viereck MJ, Maulucci CM, Sharan A, Heller J, et al: Timing in the surgical evacuation of spinal epidural abscesses. Neurosurg Focus 37(2):E1, 2014

11. Harris JH, Yeakley JW: Hyperextension-dislocation of the cervical spine. Ligament injuries demonstrated by magnetic resonance imaging. J Bone Joint Surg Br 74:567-570, 1992

12. Herkowitz HN, Rothman RH: Subacute instability of the cervical spine. Spine (Phila Pa 1976) 9:348-357, 1984

13. Hindy J, Shelef I, Slovik Y, Joshua BZ: Late prevertebral and spinal abscess following chemoradiation for laryngeal squamous cell carcinoma. Case Rep Otolaryngol 2014:425724, 2014

14. Hlavin ML, Kaminski HJ, Ross JS, Ganz E: Spinal epidural abscess: a ten-year perspective. Neurosurgery 27:177-184, 1990

15. Hsieh PC, Liu JC, Wang MY: Introduction: Vertebral osteomyelitis and spinal epidural abscess. Neurosurg Focus 37(2):Introduction, 2014

16. Ivancic PC, Pearson AM, Panjabi MM, Ito S: Injury of the anterior longitudinal ligament during whiplash simulation. Eur Spine J 13:61-68, 2004

17. Jeon SH, Han DC, Lee SG, Park HM, Shin DJ, Lee YB:
Eikenella corrodens cervical spinal epidural abscess induced by a fish bone. J Korean Med Sci 22:380-382, 2007

18. Jinkins JR, Bazan C III, Xiong L: MR of disc protrusion engendered by infectious spondylitis. J Comput Assist Tomogr 20:715-718, 1996

19. Jónsson H Jr, Bring G, Rauschning W, Sahlstedt B: Hidden cervical spine injuries in traffic accident victims with skull fractures. J Spinal Disord 4:251-263, 1991

20. Kaufman DM, Kaplan JG, Litman N: Infectious agents in spinal epidural abscesses. Neurology 30:844-850, 1980

21. Khan SH, Hussain MS, Griebel RW, Hattingh S: Title comparison of primary and secondary spinal epidural abscesses: a retrospective analysis of 29 cases. Surg Neurol 59:28-33, 2003

22. Lew DP, Waldvogel FA: Osteomyelitis. Lancet 364:369-379, 2004

23. Lin JY, Wang CH, Huang TW: Traumatic retropharyngeal hematoma: case report. Auris Nasus Larynx 34:423-425, 2007

24. Lu CH, Chang WN, Lui CC, Lee PY, Chang HW: Adult spinal epidural abscess: clinical features and prognostic factors. Clin Neurol Neurosurg 104:306-310, 2002

25. Morrison A: Hyperextension injury of the cervical spine with rupture of the oesophagus. J Bone Joint Surg Br 42-B:356357,1960

26. Nérot C, Jeanneret B, Lardenois T, Lépousé C: Esophageal perforation after fracture of the cervical spine: case report and review of the literature. J Spinal Disord Tech 15:513518,2002

27. Nurata H, Yilmaz MB, Borcek AO, Oner AY, Baykaner MK: Retropharyngeal hematoma secondary to whiplash injury in childhood: a case report. Turk Neurosurg 22:521-523, 2012

28. Nussbaum ES, Rigamonti D, Standiford H, Numaguchi Y, Wolf AL, Robinson WL: Spinal epidural abscess: a report of 40 cases and review. Surg Neurol 38:225-231, 1992

29. Patel AR, Alton TB, Bransford RJ, Lee MJ, Bellabarba CB, Chapman JR: Spinal epidural abscesses: risk factors, medical versus surgical management, a retrospective review of 128 cases. Spine J 14:326-330, 2014

30. Reihsaus E, Waldbaur H, Seeling W: Spinal epidural abscess: a meta-analysis of 915 patients. Neurosurg Rev 23:175-205, 2000

31. Reilly BK, Reilly JS: Retropharyngeal abscess: diagnosis and treatment update. Infect Disord Drug Targets 12:291-296, 2012

32. Reynolds F: Neurological infections after neuraxial anesthesia. Anesthesiol Clin 26:23-52, v, 2008

33. Richter M, Wilke HJ, Kluger P, Claes L, Puhl W: Load-displacement properties of the normal and injured lower cervical spine in vitro. Eur Spine J 9:104-108, 2000

34. Rigamonti D, Liem L, Sampath P, Knoller N, Namaguchi Y, Schreibman DL, et al: Spinal epidural abscess: contemporary trends in etiology, evaluation, and management. Surg Neurol 52:189-197, 1999

35. Robinson MH, Young JD, Burge PD: Retropharyngeal abscess, airway obstruction, and tetraplegia after hyperextension injury of the cervical spine: case report. J Trauma 32:107-109, 1992

36. Rothman RH Simeone FA: The Spine, ed 3. Philadelphia: WB Saunders, 1992, Vol 2, pp 1320-1343

37. Sampath P, Rigamonti D: Spinal epidural abscess: a review of epidemiology, diagnosis, and treatment. J Spinal Disord 12:89-93, 1999

38. Schimmer RC, Jeanneret C, Nunley PD, Jeanneret B: Osteomyelitis of the cervical spine: a potentially dramatic disease. J Spinal Disord Tech 15:110-117, 2002

39. Sendi P, Bregenzer T, Zimmerli W: Spinal epidural abscess in clinical practice. QJM 101:1-12, 2008 
40. Shah NH, Roos KL: Spinal epidural abscess and paralytic mechanisms. Curr Opin Neurol 26:314-317, 2013

41. Shea M, Wittenberg RH, Edwards WT, White AA III, Hayes WC: In vitro hyperextension injuries in the human cadaveric cervical spine. J Orthop Res 10:911-916, 1992

42. Siddiq F, Chowfin A, Tight R, Sahmoun AE, Smego RA Jr: Medical vs surgical management of spinal epidural abscess. Arch Intern Med 164:2409-2412, 2004

43. Splener CW, Benfield JR: Esophageal disruption from blunt and penetrating external trauma. Arch Surg 111:663-667, 1976

44. Srinivasan D, Terman SW, Himedan M, Dugo D, La Marca F, Park P: Risk factors for the development of deformity in patients with spinal infection. Neurosurg Focus 37(2):E2, 2014

45. Stringer WL, Kelly DL Jr, Johnston FR, Holliday RH: Hyperextension injury of the cervical spine with esophageal perforation. Case report. J Neurosurg 53:541-543, 1980

46. Tang HJ, Lin HJ, Liu YC, Li CM: Spinal epidural abscessexperience with 46 patients and evaluation of prognostic factors. J Infect 45:76-81, 2002

47. Tominaga $\mathrm{Y}, \mathrm{Ndu} \mathrm{AB}$, Coe MP, Valenson AJ, Ivancic PC, Ito $S$, et al: Neck ligament strength is decreased following whiplash trauma. BMC Musculoskelet Disord 7:103, 2006

48. Ueki Y, Watanabe J, Hashimoto S, Takahashi S: Cervical spine osteomyelitis and epidural abscess after chemoradiotherapy for hypopharyngeal carcinoma: a case report. Case Rep Otolaryngol 2014:141307, 2014

49. Uhrenholt L, Freeman MD, Jurik AG, Jensen LL, Gregersen M, Boel LW, et al: Esophageal injury in fatal rear-impact collisions. Forensic Sci Int 206:e52-e57, 2011

50. Wadie GM, Konefal SH, Dias MA, McLaughlin MR: Cervical spondylodiscitis from an ingested pin: a case report. J Pediatr Surg 40:593-596, 2005
51. Waldvogel FA, Medoff G, Swartz MN: Osteomyelitis: a review of clinical features, therapeutic considerations and unusual aspects. 3. Osteomyelitis associated with vascular insufficiency. N Engl J Med 282:316-322, 1970

52. Waldvogel FA, Papageorgiou PS: Osteomyelitis: the past decade. N Engl J Med 303:360-370, 1980

53. Wheeler D, Keiser P, Rigamonti D, Keay S: Medical management of spinal epidural abscesses: case report and review. Clin Infect Dis 15:22-27, 1992

54. Yoganandan N, Cusick JF, Pintar FA, Rao RD: Whiplash injury determination with conventional spine imaging and cryomicrotomy. Spine (Phila Pa 1976) 26:2443-2448, 2001

\section{Disclosure}

The authors report no conflict of interest concerning the materials or methods used in this study or the findings specified in this paper.

\section{Author Contributions}

Conception and design: Goulart, Mattei. Acquisition of data: Goulart, Mattei, Fiore. Analysis and interpretation of data: Goulart, Mattei. Drafting the article: Goulart, Mattei. Critically revising the article: all authors. Reviewed submitted version of manuscript: all authors. Approved the final version of the manuscript on behalf of all authors: Goulart. Study supervision: Mendel.

\section{Correspondence}

Carlos R. Goulart, Department of Neurosurgery, The Ohio State University, The James Cancer Hospital, N-1037 Doan Hall, 410 W. 10th Ave., Columbus, OH 43210. email: carlosgoulart2010@ gmail.com. 